\title{
Simple Correlations between Rock Abrasion and Other Significant Rock Properties for Rock Mass and Intact Quartzite
}

\author{
Scott Ureel, Moe Momayez \\ Department of Mining \& Geological Engineering, University of Arizona, Tucson, AZ, USA \\ Email: scott.ureel@gmail.com
}

How to cite this paper: Ureel, S. and Momayez, M. (2017) Simple Correlations between Rock Abrasion and Other Significant Rock Properties for Rock Mass and Intact Quartzite. Open Journal of Civil Engineering, 7, 194-207.

https://doi.org/10.4236/ojce.2017.72012

Received: February 15, 2017

Accepted: June 3, 2017

Published: June 6, 2017

Copyright $\odot 2017$ by authors and Scientific Research Publishing Inc. This work is licensed under the Creative Commons Attribution International License (CC BY 4.0).

http://creativecommons.org/licenses/by/4.0/

\begin{abstract}
Rock abrasion plays a significant role in geotechnical design, tunneling operations and the safety of foundations from scour. It is imperative to determine such properties of uniaxial compression strength (UCS), rock quality designation (RQD) and hardness for rock engineering to help determine the amount of scour at foundation locations in order to prevent structural collapse, wear on drilling tools and help predict unstable rock conditions. Current practice for estimating maximum rock abrasion is based on the Los Angeles abrasion test; however, more research is needed to provide a more accurate and compatible method for all subsurface materials used in mining and civil engineering projects. This report will provide simple correlations relating abrasion resistance to RQD, UCS, Geological Strength Index (GSI) and Rock Mass Rating (RMR) and shear strength of metamorphic rock (Quartzite). Methods, results, recommendations and conclusions are presented. The paper also introduces recommendations for future rock abrasion techniques and discusses the use of these correlations exhibiting strong relationships between the mentioned rock properties.
\end{abstract}

\section{Keywords}

Rock Abrasion, RQD, UCS, Shear Strength, LA Abrasion

\section{Introduction}

Rock quality designation (RQD), Uniaxial Compression Strength (UCS), hardness and rock abrasion all place a significant role in rock mechanics. Like RQD, hardness exhibits the quality of the rock where the UCS provides strength of the rock. Abrasion resistance of rock combines both the strength (binding material) and quality of the rock (how broken the material can become). Rock abrasion 
can be defined as the process of wearing away a surface by friction when particles of sand or small pieces of rock are carried across its surface by a glacier, stream, other materials or the wind. Noted and tested by [1] Okubo et al. (2011), rock abrasion resistance has a direct relationship with the wear occurring in the bits of rock drills, road headers, tunnel boring machines and other equipment, and has long been researched; however, further rock properties may be correlated to help predict wear of mining equipment, slope stability and underground rock conditions. Other notable past research indicating the need for further rock abrasion testing and showing distinct correlations between rock abrasion and other rock properties include [2] Yavuz et al. (2008), [3] Cargill and Shakoor (1990), [4] Kulıç and Teymen (2008), and [5] Petrica et al. (2013). As mentioned by [6] Kahraman \& Gunaydin (2007), the boundaries and pores between grains represent weaknesses in the rock structure and failure of rocks generally takes place at the grain boundaries. Therefore, rock abrasion and RQD can be correlated according to the strength of the rock.

$\mathrm{RQD}$ is a field measurement to estimate the degree of fracturing in a rock mass in situ. RQD value depends on a number of parameters such as the state of in-situ stress, direction of drilling, degree of weathering, amount of jointing and is used as one parameter to determine rock mass rating (RMR). As the RQD percentage value increases, the less amount of fracturing should be observed and the quality of rock should improve. Like RQD, LA abrasion resistance is measured on a 0 to 100 percentage scale to determine the amount of material loss due to erodibility factors (i.e. wind, grinding, impact). LA Abrasion test results will indicate if a material (rock) is susceptible to wear indirectly by crushability; hence, will show how "intact" a rock mass is. Intact rock can be defined as the rock sections between fractures of the rock mass and do not contain major fractures within. A low RQD value will indicate higher weathering and contain less abrasion resistance due to lower hardness and intact strength properties. LA Abrasion like RQD can show an indirect relationship indicating the quality (rock mass) and strength (intact rock) as well as showing how cohesive rock specimens are. The higher the weathering and less cohesive the rock (regardless if intact or rock mass), the less the abrasion resistance and RQD will be. RQD and LA Abrasion property also have been used in comparison to determine scourability of bedrock of bridge foundations. Higher RQD and rock abrasion resistance will produce less scour potential. This paper investigated and compared LA Abrasion and RQD based on both rock mass and intact rock properties. The paper also proposes results using LA Abrasion testing to correlate RQD, shear strength, Geological Strength Index (GSI) and Rock Mass Rating (RMR) and UCS. Results, recommendations and conclusions are presented in the paper.

\section{Materials and Methods}

A key aspect for obtaining properties of intact rock, fracture strength and rock masses is laboratory and field testing or measurements. Through laboratory 
testing essential properties can be used to understand rock behavior, composition and abrasion resistance. Numerous laboratory properties were gathered in order to provide significant information relating rock hardness, RQD and abrasion. The following section describes the tests performed and the results acquired to create correlations and relationships between the rock properties mentioned above. These laboratory and field measurements include:

- Uniaxial Compression Testing,

- Brazilian Disk Tension Testing,

- Triaxial Compression Testing,

- LA Abrasion Testing,

- Rock Quality Designation (field),

- Hardness (field).

The stresses obtained from uniaxial compression, triaxial compression and Brazilian disk tension intact testing develop a general strength criterion exhibited in Figure 1. Negative $\sigma 3$ values indicate rock in tension obtained from the Brazilian disk testing. For this investigation, numerous core samples were taken from a large mining operation in the western United States. All samples were taken from the same rock type which consisted of quartzite or hornfels/quartzite and from nearby drill holes keeping the consistency of weathering and alteration. Field hardness and RQD were taken for all samples. The samples were then tested to develop an intact strength criteria and LA Abrasion testing was performed from the crushed broken samples. Rock hardness was measured in the field using a geological pick, knife or thumbnail depending on the hardness of the rock. Table 1 exhibits the ranges and procedures for measuring the hardness of rock using both visual and based on the UCS of the rock.

RQD was administered during core logging and based on the methods introduced by [8] Deere et al. (1967). The procedure of the measuring RQD is shown in Figure 2 and the basic equation to determine RQD is:

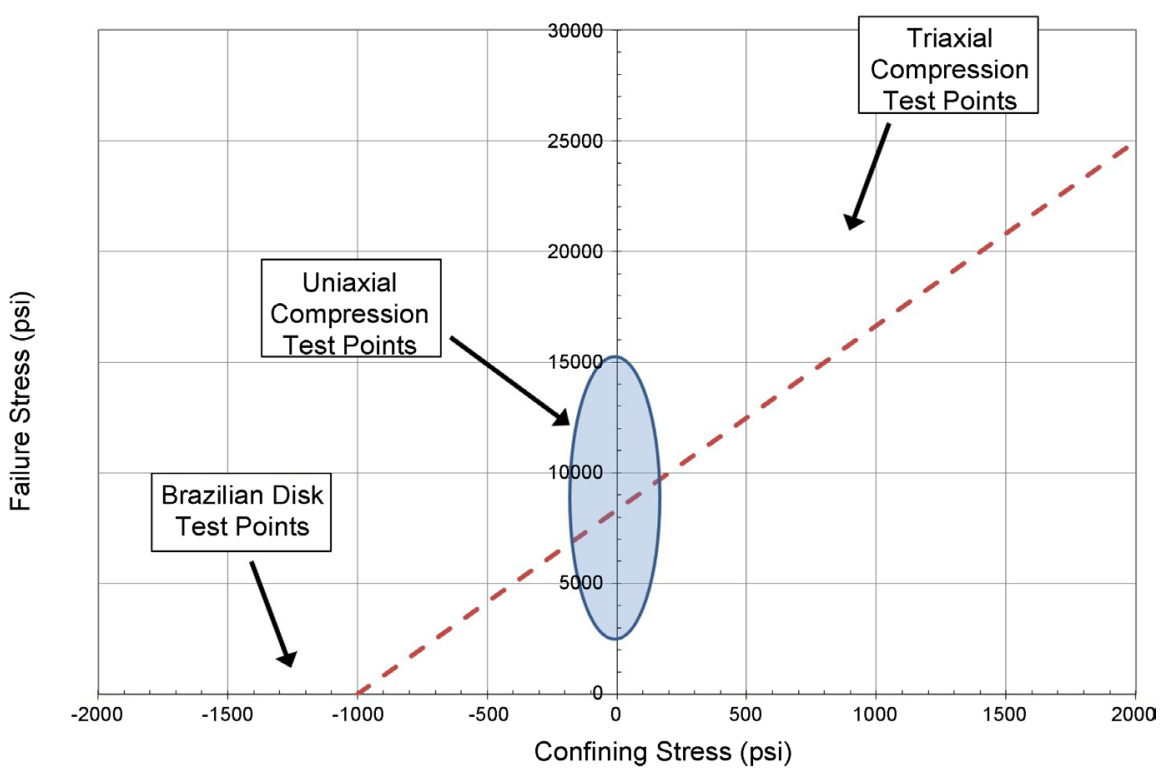

Figure 1. General failure stress vs. confining stress from intact testing. 
Table 1. Relationship between hardness, consistency and uniaxial compressive strength [7] (after Call \& Nicholas, 2008).

\begin{tabular}{|c|c|c|c|c|}
\hline \multicolumn{3}{|r|}{ Rock Characteristics } & \multicolumn{2}{|c|}{$\begin{array}{l}\text { Approximate Range of Unconfined } \\
\text { Compressive Strength }\end{array}$} \\
\hline Hardness & Consistency & Field Identification & PSI & $\mathrm{MPa}$ \\
\hline R0 & extremely soft rock & Indented by thumbnail & $28-100$ & $0.19-0.69$ \\
\hline R1 & very soft rock & $\begin{array}{l}\text { Crumbles under firm blows with point of geologic pick, can be peeled by a } \\
\text { pocket knife }\end{array}$ & $100-1000$ & $0.69-6.9$ \\
\hline $\mathrm{R} 2$ & soft rock & $\begin{array}{l}\text { Can be peeled by a pocket knife with difficulty, shallow indentations made by } \\
\text { firm blow of geological pick }\end{array}$ & $1000-4000$ & $6.9-27.6$ \\
\hline R3 & average rock & $\begin{array}{l}\text { Cannot be scraped or peeled with a pocket knife, specimen can be fractured } \\
\text { with single firm blow of hammer end of geological pick }\end{array}$ & $4000-8000$ & $27.6-55.2$ \\
\hline $\mathrm{R} 4$ & hard rock & Specimen required more than one blow with hammer end of pick to fracture it & $8000-16,000$ & $55.2-110.3$ \\
\hline R5 & very hard rock & Specimen required many blows of hammer end of geological pick to fracture it & $16,000-32,000$ & $110.3-220.6$ \\
\hline R6 & extremely hard rock & Specimen can only be chipped with geological pick & $>32,000$ & $>220.6$ \\
\hline
\end{tabular}
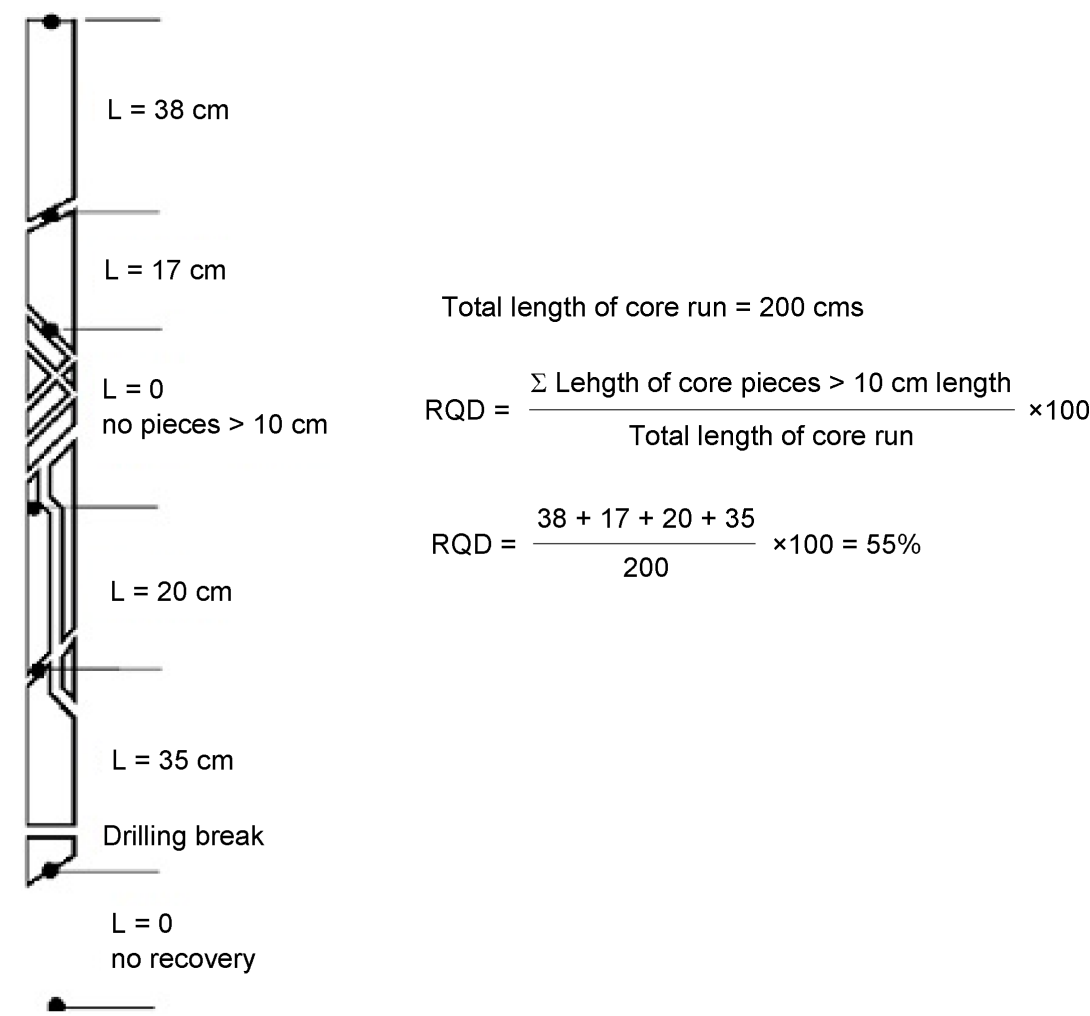

Figure 2. RQD procedure and calculations [8] (Deere et al., 1967).

$$
\mathrm{RQD}=\sum_{i=1}^{n} \frac{(\text { Length of piece }>x) i}{L} \times 100
$$

where $x=4$ in. or $10 \mathrm{~cm}$., $L=$ total length of core, $N=$ number of pieces greater than $x$.

Abrasion resistance can be estimated using the LA abrasion testing method. The LA abrasion test (ASTM C131-06) was developed to determine the durability of gravel or crushed rock for use in concrete and asphalt pavements. The method was performed using crushed tested samples at $37.5 \mathrm{~mm}$. or smaller us- 
ing a sample size of roughly $5 \mathrm{~kg}$. The sample is then placed in a rotating steel cage with specified amount of steel spheres (Figure 3 ) that "abrade" the material for a certain amount of revolutions (500 in each test). This method provides an estimation of rock loss and durability; however, it does not have "direct contact" with the rock specimen of interest which leaves openings for uncertainty. Figure 4 below exhibits the set up for the LA abrasion test.

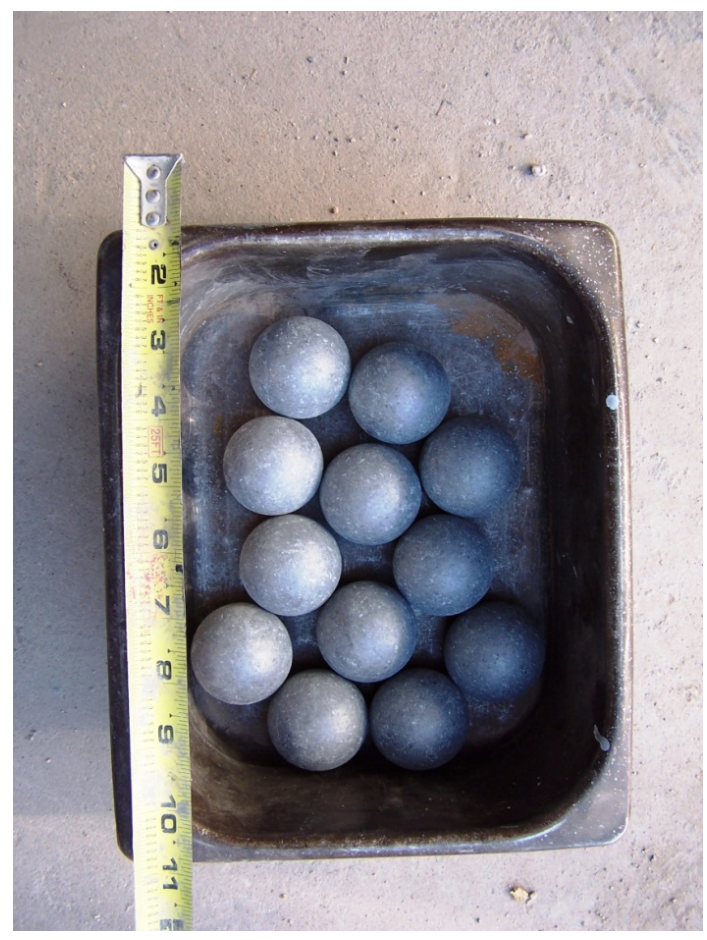

Figure 3. Steel spheres used in LA Abrasion steel cage.

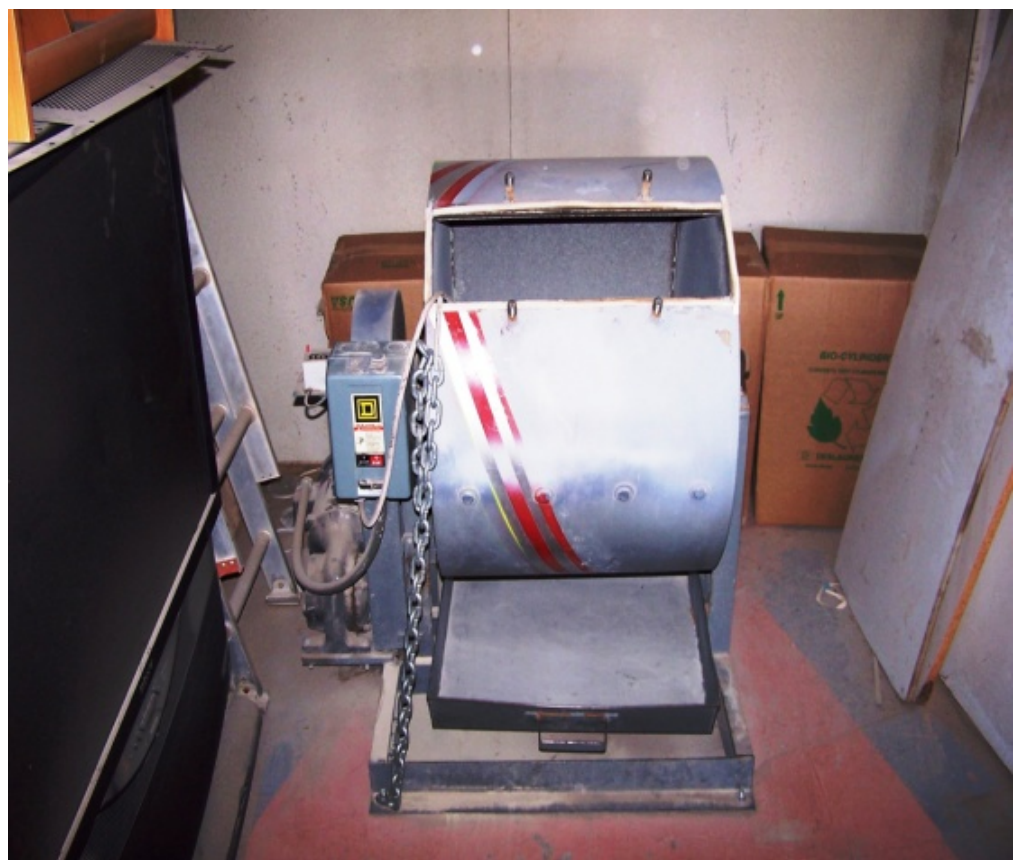

Figure 4. Basic LA abrasion test. 
The laboratory-testing program this section focused on testing a suite of similar rock types from drill holes in close proximity to each other. The rock samples were taken from twelve different boreholes that were drilled at a large mining operation in the Western United States. The prevalent rock type at the mine site is metamorphic quartzite. Even though the mining operation has unlimited rock samples, only a limited number of samples were tested due to time, cost and rock core available. Once the samples were collected they were taken to a rock mechanics laboratory and tested. The following tests were performed on select samples:

- Uniaxial Compression,

- Triaxial Compression,

- LA Abrasion,

- Brazilian Disk Tension.

A total of 64 samples were collected from the drill holes. From the samples, 29 disk tension tests, 16 triaxial compression test and 16 uniaxial compression tests were conducted. The RQD and hardness were taken in the field for each sample. Section 3 explains all testing and procedures in detail. After the samples were tested for rock strength, the broken sample pieces were crushed to 3/2". The crushed samples were then used for the LA Abrasion tests according to ASTM C131-Grading A. During this study, no small scale direct shear tests were performed; however, the following equation based on the Mohr-Coulomb failure criterion for intact rock was utilized in order to determine shear strength of the intact rock samples:

$$
\mathrm{UCS}=2 \mathrm{CTan}[\beta]
$$

where $C=$ cohesion, UCS = uniaxial compression strength, $\beta=$ slope of the $\sigma 1$ vs. $\sigma 3$ intact strength criteria $=45+\varnothing / 2$.

\section{Results}

The results from the rock samples, field and abrasion testing were analyzed using different computational methods to understand the correlations between each rock property. Each plot exhibits the correlation equation and the coefficient of determination of the data. For each LA Abrasion test, corresponding UCS, RQD and hardness values were used for the analysis. The values were then plotted to see if a high correlation or relationships exist between the rock properties of interest. Linear, exponential and power curve fitting techniques were used to determine the highest correlation through the least squares regression method and visual examination. Twelve rock strength criteria were constructed from the laboratory testing. Due to the amount of material needed and cost of the LA Abrasion test, only 7 tests were performed. Table 2 shows the results for the material testing. Figure 5 shows the plotted raw data of RQD vs. LA Abrasion loss.

In order to determine if any correlations exist between LA Abrasion resistance and other geomechanical properties used for slope stability, this section also 
Table 2. Results for material testing on metamorphic rock (quartzite).

\begin{tabular}{ccccccc}
\hline $\begin{array}{c}\text { Rock Abrasion Loss } \\
(\%)\end{array}$ & $\begin{array}{c}\text { UCS } \\
(\mathrm{MPa})\end{array}$ & $\begin{array}{c}\text { RQD } \\
(\%)\end{array}$ & $\begin{array}{c}\text { Friction Angle } \\
(\mathrm{deg})\end{array}$ & $\begin{array}{c}\text { Cohesion } \\
(\mathrm{MPa})\end{array}$ & $\begin{array}{c}\text { Shear Strength } \\
(\mathrm{MPa})\end{array}$ & GSI \\
\hline 29 & 119.1 & 79 & 50.5 & 21.4 & 165.8 & 80 \\
35 & 49.1 & 94 & 44.8 & 10.2 & 59 & 70 \\
42 & 28.2 & 73 & 38 & 6.9 & 28.9 & 55 \\
42 & 23.8 & 64 & 37.5 & 5.9 & 24.1 & 50 \\
42 & 77.6 & 88 & 40 & 18.1 & 83.2 & 65 \\
42 & 49 & 96 & 46.1 & 9.8 & 60.7 & 60 \\
47 & 51.5 & 95 & 44.7 & 10.7 & 61.7 & 45 \\
56 & 44.6 & 74 & 45.9 & 9 & 55 & 40 \\
\hline
\end{tabular}

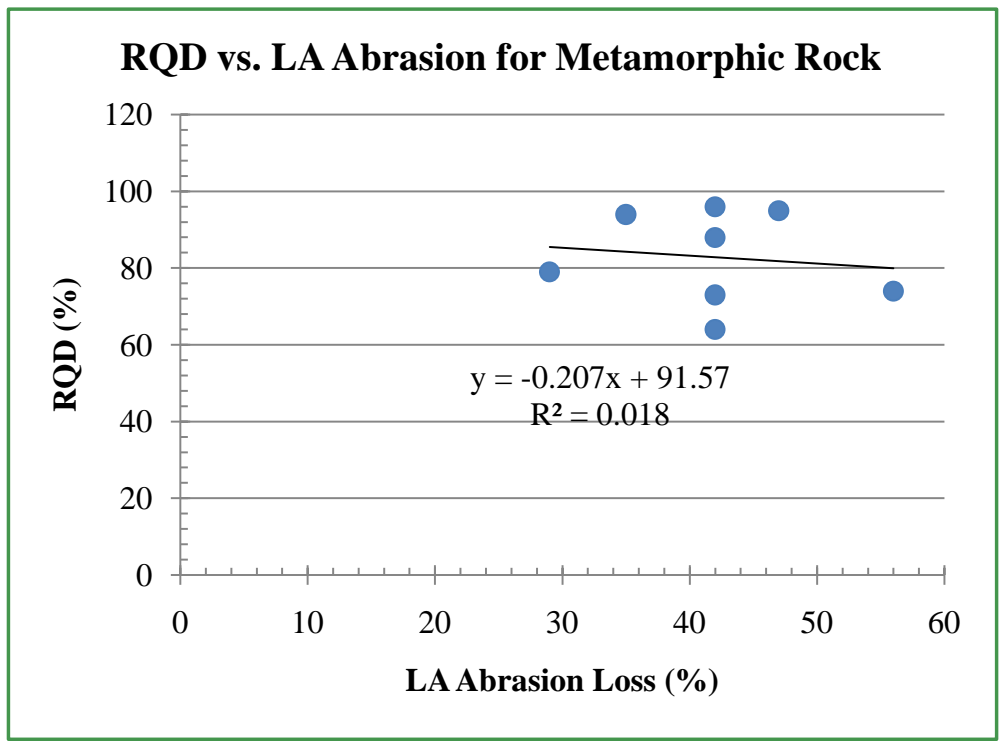

Figure 5. RQD vs. LA abrasion loss.

examined geological strength (GSI), Rock Mass Rating (RMR) and shear strength. The GSI is a rock rating system created by [9] Hoek \& Brown (1997) used to estimate the rock mass strength. GSI is determined by visually observing the rock structure rated from blocky to disintegrated and surface rock conditions rate very poor to very good. From these conditions and reviewing field and laboratory data, a GSI value can be assigned to classify rock by using the rock rating system. All samples were inspected by an expert geologist and the author and assigned GSI values. All samples were inspected and assigned GSI values. The summary of the chosen samples is shown in Table 2. The GSI values were plotted against the abrasion loss percentages and produced a high correlation $\left(\mathrm{R}^{2}=\right.$ 0.86 ) as shown in Figure 6.

After examining the relationship of GSI and rock abrasion, a similar approach was taken by comparing the Rock Mass Rating (RMR) and rock abrasion. Like the GSI, the RMR also estimates rock mass strength; however, the RMR estimates rock strengths according to six rock conditions rather than rock structure. The RMR is based on UCS, RQD, joint spacing, joint conditions, groundwater 
conditions and if the orientation is favorable or unfavorable. The RMR classifies rock very poor 0 - 20, poor 21 - 40, fair 41 - 60, good 61 - 80 and very good 81 100. The orientation rating was omitted to maintain an unbiased RMR value. All samples were classified according to the Rock Mass Rating system [10] (after Bieniawski, 1989). The summary of rock samples selected is shown in Table 3. It should be noted the RMR values are all estimated. The RMR values were plotted against the abrasion loss percentages and produced a high correlation $\left(\mathrm{R}^{2}=0.87\right)$ as shown in Figure 7.

Lastly, shear strengths were determined using the relationship based on the intact strength criteria ( $\sigma 1$ vs. $\sigma 3$ ) and mentioned in the previous section. The Mohr Coulomb shear strength equation was applied using the corresponding sample UCS value as the normal stress applied. Table 2 displays the results obtained from the field, laboratory testing and the calculated shear strength.

The shear strength was then plotted against the corresponding RQD and LA Abrasion values. Figure 8 displays the raw data of the shear strength vs. LA Abrasion that produces a low to medium linear correlation with $\mathrm{R}^{2}=0.34$. Figure 9

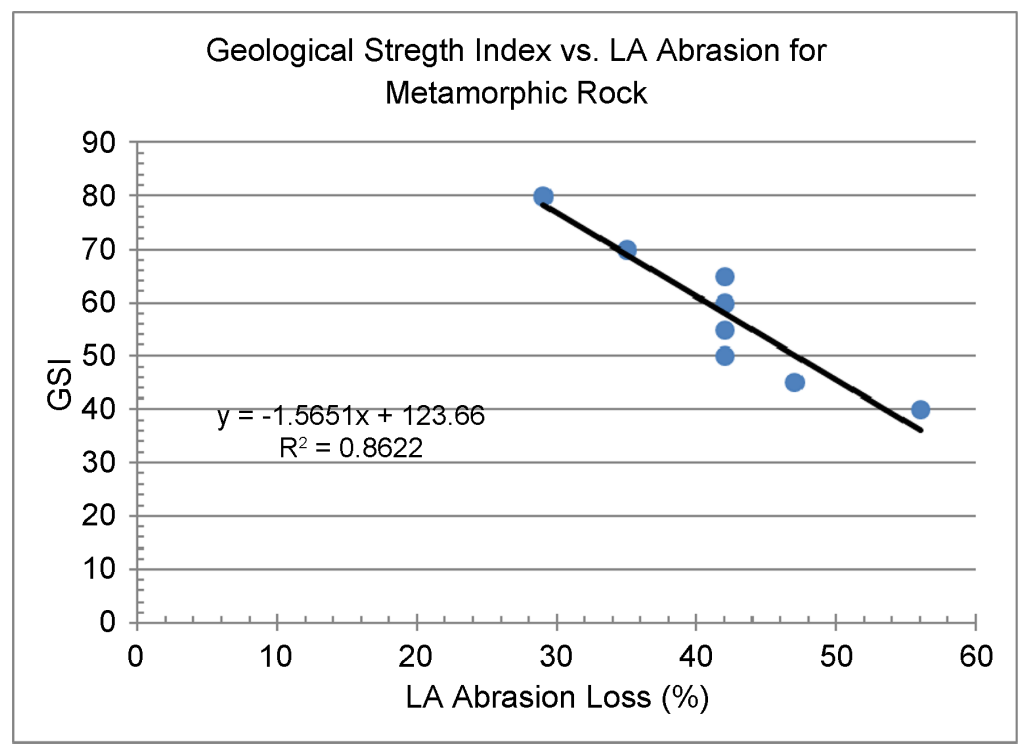

Figure 6. GSI vs. rock abrasion loss for metamorphic rock (linear trend).

Table 3. Rock mass rating for selected rock samples.

\begin{tabular}{ccccccc}
\hline $\begin{array}{c}\text { UCS } \\
\text { Rating }\end{array}$ & $\begin{array}{c}\text { RQD } \\
\text { Rating }\end{array}$ & $\begin{array}{c}\text { Joint Spacing } \\
\text { Rating }\end{array}$ & $\begin{array}{c}\text { Groundwater } \\
\text { Rating }\end{array}$ & $\begin{array}{c}\text { Joint Condition } \\
\text { Rating }\end{array}$ & RMR & $\begin{array}{c}\text { Rock } \\
\text { Category }\end{array}$ \\
\hline 12 & 17 & 10 & 10 & 30 & 79 & Good \\
7 & 20 & 15 & 10 & 20 & 72 & Good \\
4 & 13 & 10 & 10 & 20 & 57 & Fair \\
2 & 13 & 8 & 10 & 20 & 53 & Fair \\
7 & 17 & 15 & 10 & 10 & 59 & Fair \\
4 & 20 & 15 & 10 & 10 & 59 & Fair \\
7 & 20 & 15 & 10 & 0 & 52 & Fair \\
4 & 13 & 10 & 10 & 10 & 47 & Fair \\
\hline
\end{tabular}




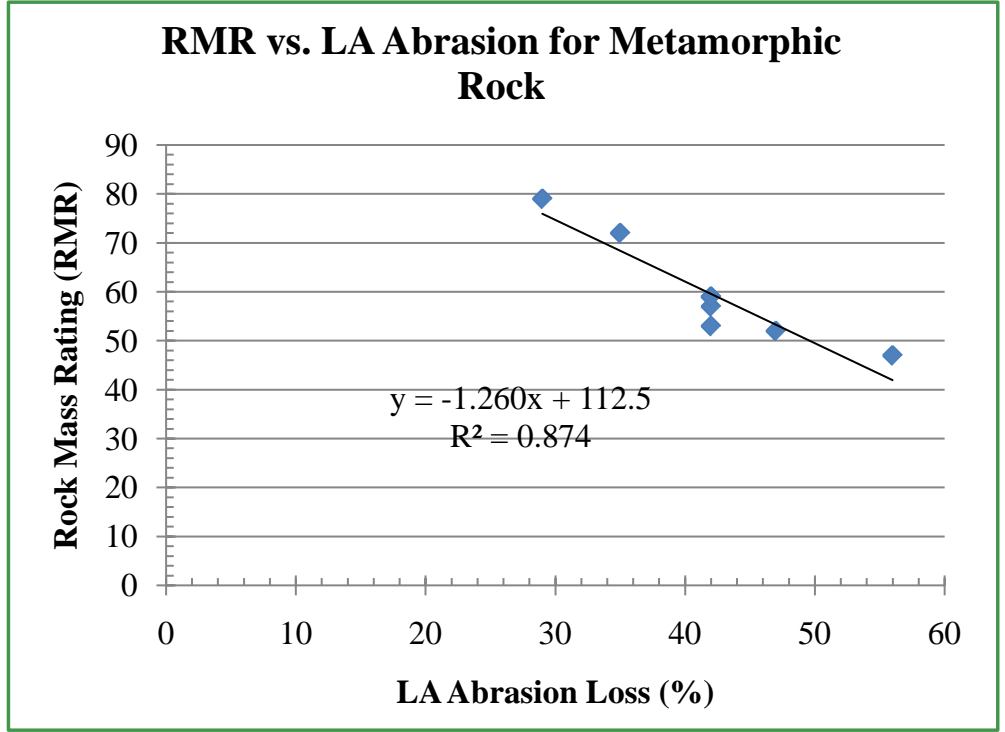

Figure 7. RMR vs. LA abrasion loss for metamorphic rock.

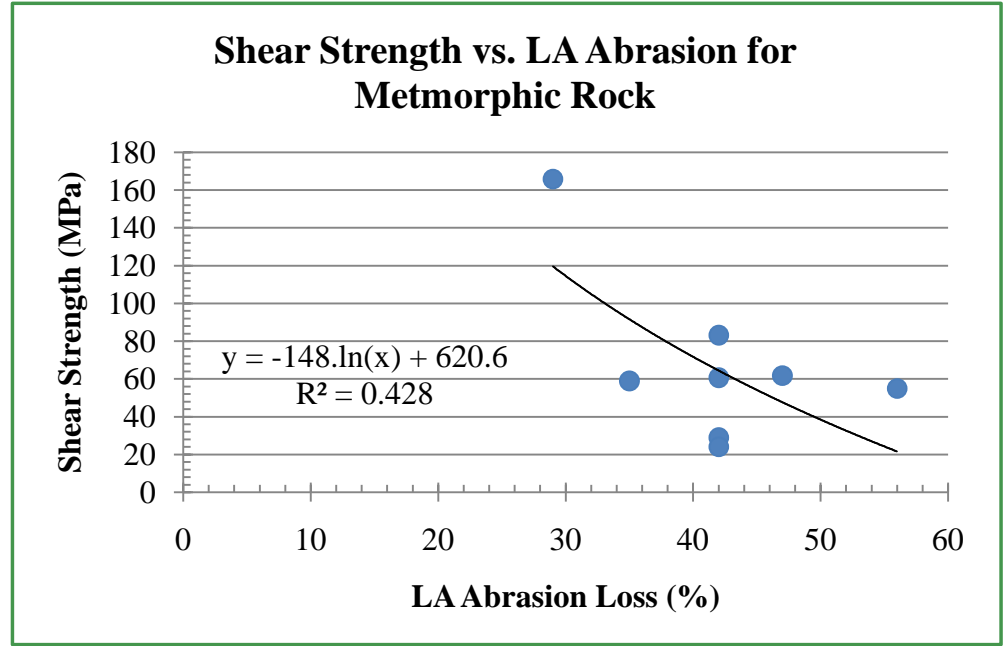

Figure 8. Shear strength vs. LA abrasion for metamorphic rock.

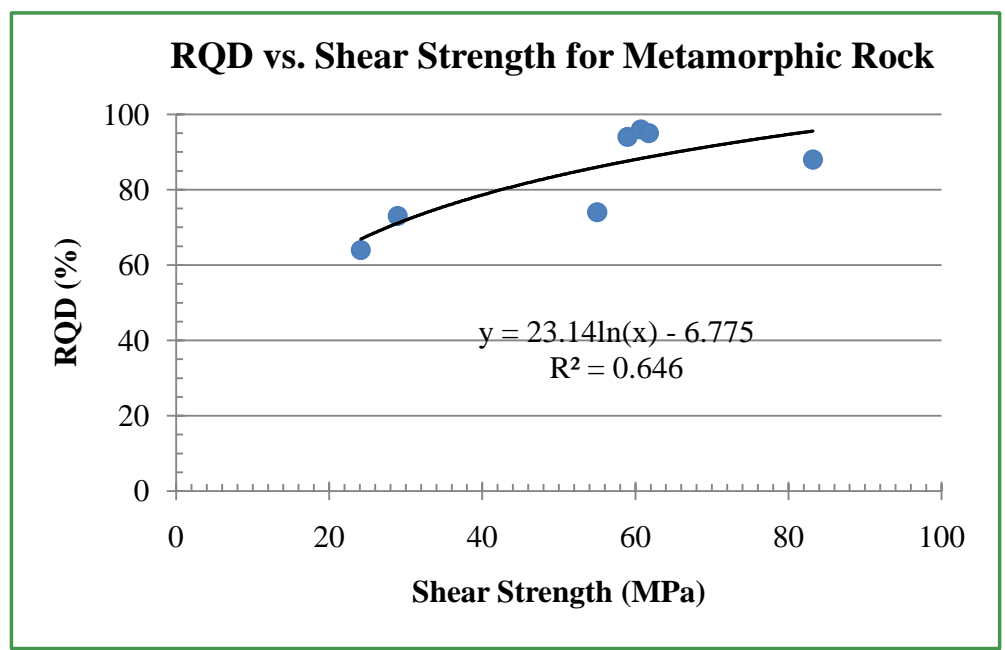

Figure 9. RQD vs. shear strength for metamorphic rock (logarithmic trend). 
shows the results when RQD vs. shear strength values are plotted. This calculates a medium correlation of $\mathrm{R}^{2}=0.67$.

\section{Discussion}

After the field and laboratory data has been completed, explanation and verification are needed to understand the relationships between RQD, LA Abrasion and other significant rock properties. The following sections will discuss the bias in data, the results obtained from the laboratory and field results and the potential future research needed to further understand the correlations between the mentioned rock properties.

\subsection{Uniaxial Compression Strength, Rock Abrasion, Rock Quality Designation}

[11] Kahraman and Fener (2007) performed numerous LA abrasion and uniaxial compression tests to understand correlations between the two parameters. Similar testing was performed by [6] Kahraman and Gunaydin (2007); however, point load testing and the Schmidt hammer were utilized instead of uniaxial compression testing. Figure 10 shows high comparison from [11] Kahraman and Fener (2007) and this study indicating strong relationship between UCS and LA Abrasion and verifies the values obtained.

Though it appears for the constructed plots that no strong correlation exists between RQD and LA abrasion, a large sampling program may increase the correlation due to a larger range of values. The testing and field results maintained a small range of 29 to 56 percent for abrasion loss and 64 to 96 percent for RQD. Both ranges have a difference of about almost 30 percent; however, the ranges lie in different positions among the similar scale of 0 to 100 percent. Theoretically for the relationship of RQD to LA Abrasion to correlate well, the values obtained from rock samples need to have the same indirect ranges and values (ex: LA Abrasion loss $=15$ percent, $\mathrm{RQD}=85$ percent). The differences of the values fall on

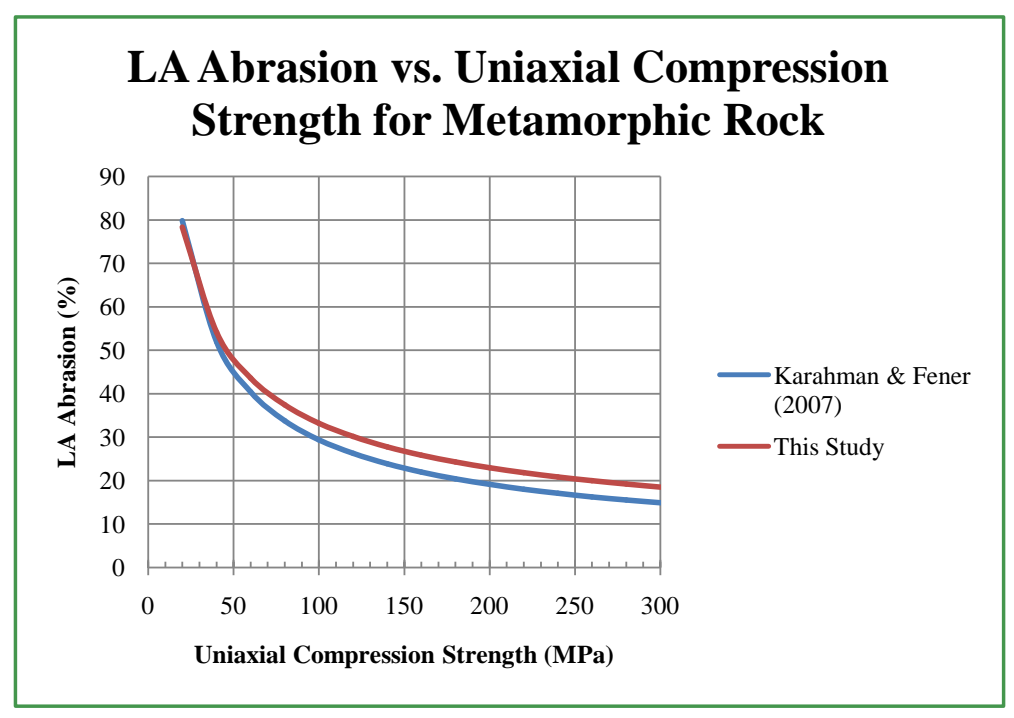

Figure 10. Comparison of LA abrasion vs. UCS for metamorphic rock. 
the 0 - 100 percent scale indicate one or more rock properties is needed to predict RQD instead of RQD solely based from rock abrasion resistance. This is similar to if RQD was plotted against UCS except the data displays much scatter. The plots do show some trend; however, it is not conclusive that a correlation exists.

\subsection{Uniaxial Compression Strength, Rock Abrasion, Rock Mass Rating and Geological Strength Index}

Since the GSI and RMR systems include (depending on the rock characterization method used) rock structure, field observations and UCS values, the LA Abrasion data can be used to classify the rock samples accordingly. High correlations exist between RMR and LA Abrasion loss and GSI and La Abrasion loss. It seems GSI applies more to rock abrasion and RQD comparisons than RMR due to GSI being based on rock mass fractures, block size and rock conditions at the surface. However, the RMR characterization does include RQD as a factor when classifying the rock mass. Though the GSI and RMR vs. rock abrasion results show high correlation ( $R^{2}$ above 0.8$)$, the results are biased due to estimation. Both the RMR and GSI have RQD are involved in the classification of the rock mass; however, other factors such as joint conditions, block size and groundwater conditions with help dictate the outcome of the results.

\subsection{Shear Strength, Rock Abrasion and Rock Quality Designation}

From all rock properties, shear strength exhibits the highest correlation with RQD. A medium correlation $\left(\mathrm{R}^{2}=0.65\right) \mathrm{RQD}$ vs. shear strength may due to the fact that the shear strength is based on how cohesive (interlocking grain strength) the material is and the amount friction (phi) between the rock grains. One of the main factors effecting abrasion resistance is the amount of friction between two entities. The correlation between LA Abrasion and shear strength provide a medium correlation $\left(\mathrm{R}^{2}=0.43\right)$.

\subsection{Summary of Rock Properties Correlations}

Transformations can be considered once laboratory and field testing is completed and data is compiled. The coefficient of determination $\left(R^{2}\right)$ shown in the plots above indicate how well the data points fit in the statistical model or the measure of predictability of the variance in the regressions. Some plots showed a high coefficient of determination; however, further justification is warranted. The correlation coefficient (R) gives the degree of correlation between two sets of data. The following tables presented show multiple linear regressions created from Matlab with the correlation coefficients provided from the original data and a trial of adjusted data points that included transforming the RQD data to $1 / \mathrm{RQD}$. The 1/RQD was used in order to observe if the sign of the abrasion to RQD correlation coefficient changes from positive to negative to obtain correlation coefficients with same signage. Table 4 and Table 5 illustrate the results and correlations coefficients for both the original and adjusted data. 
A simple linear regression can be constructed using UCS as the independent variable and abrasion as the dependent variable. Next, a multiple linear regression can be constructed and calculated using all variables. Since the correlation coefficient between abrasion and RQD is very low, the RQD variable was taken out of the dataset and the regression was calculated again. Table 6 below exhibits the results from the linear and multiple regressions.

From the dataset analyses, it is shown that abrasion and UCS provide the highest correlation $(-0.6737)$ among all the variables. The multiple regression using all the variables provides an even higher correlation at -0.8015 . The results also show that if you do not include the lowest correlation of RQD and abrasion, the correlation coefficient does not increase. This is not what is expected; however, the analysis shows there is possibly a significant correlation between the geomechnical properties and rock abrasion.

The linear and power law relationship still holds when more RQD and Abrasion data points added and indicates a more rigorous relationship between RQD

Table 4. Correlation coefficients for the original data.

\begin{tabular}{cccccc}
\hline Abrasion & UCS & RQD & Hardness & Friction Angle & Cohesion \\
\hline 1 & -0.6737 & 0.1179 & -0.5638 & -0.592 & -0.5781 \\
-0.6737 & 1 & 0.213 & 0.8926 & 0.7326 & 0.9764 \\
0.1179 & 0.213 & 1 & 0.3514 & 0.5329 & 0.2261 \\
-0.5638 & 0.8926 & 0.3514 & 1 & 0.7292 & 0.868 \\
-0.592 & 0.7326 & 0.5329 & 0.7292 & 1 & 0.6026 \\
-0.5781 & 0.9764 & 0.2261 & 0.868 & 0.6026 & 1 \\
\hline
\end{tabular}

Table 5. Correlation coefficients for the adjusted data.

\begin{tabular}{cccccc}
\hline Abrasion & UCS & RQD & Hardness & Friction Angle & Cohesion \\
\hline 1 & -0.6737 & -0.0629 & -0.5638 & -0.592 & -0.5781 \\
-0.6737 & 1 & -0.2855 & 0.8926 & 0.7326 & 0.9764 \\
-0.0629 & -0.2855 & 1 & -0.4271 & -0.56 & -0.3015 \\
-0.5638 & 0.8926 & -0.4271 & 1 & 0.7292 & 0.868 \\
-0.592 & 0.7326 & -0.56 & 0.7292 & 1 & 0.6026 \\
-0.5781 & 0.9764 & -0.3015 & 0.868 & 0.6026 & 1 \\
\hline
\end{tabular}

Table 6. Summary of regression calculations and dataset.

\begin{tabular}{|c|c|c|c|c|}
\hline $\begin{array}{c}\text { Abrasion } \\
\text { Regression Type }\end{array}$ & $\begin{array}{l}\text { Variables } \\
\text { Used }\end{array}$ & $\begin{array}{c}\text { Coefficient of } \\
\text { Determination } \mathrm{R}^{2}\end{array}$ & Predicted Abrasion Equation & $\begin{array}{c}\text { Correlation } \\
\text { Coefficient R }\end{array}$ \\
\hline Linear & UCS & 0.4539 & $46.8348-0.1227 * \mathrm{UCS}$ & -0.6737 \\
\hline Multiple & All & 0.6424 & $\begin{array}{c}72.126-0.2574 * \mathrm{UCS}-1092.9051 * \\
\text { RQD }-0.0348 * \text { Hardness }-0.3438 * \\
\text { Friction Angle }+0.8909 * \text { cohesion }\end{array}$ & -0.8015 \\
\hline Multiple & $\begin{array}{l}\text { All except } \\
\text { RQD }\end{array}$ & 0.6372 & $\begin{array}{c}18.3729-0.7031 * \text { UCS }+0.3611 * \\
\text { Hardness }+0.5880 * \text { Friction Angle }+ \\
0.5880 * \text { cohesion }\end{array}$ & -0.7983 \\
\hline
\end{tabular}


and abrasion. If four data points are added to expand the limited range of LA and RQD values, a correlation of $\mathrm{R}^{2}=0.7$ is calculated. This was assuming values one might expect when graphing RQD vs. LA (high RQD = low abrasion loss, low RQD = high abrasion loss). Figure 11 below exhibits this. This means further testing is valid and more samples with High RQD (high abrasion resistance) or Low RQD (low abrasion resistance) are needed.

\section{Conclusions}

In conclusion, testing abrasion resistance and correlating it to other rock parameters such as RQD can be an intensively time consuming task. The purpose of this paper was to inform the engineering community of potential future research for rock abrasion and suggest possible methods to obtain reliable data. From the resulting correlation plots, the strong relationship display a good prediction tool for RQD based from the UCS and hardness of the rock. However, this will only be achieved with ongoing sampling and testing. Future research regarding rock abrasion resistance can be recommended. The following is a list of recommendations when introducing new research for rock abrasion:

- Data from all rock types should be collected,

- Create ranges for RQD determined from direct abrasion data,

- Perform abrasion resistance testing to many more specimens rather than only rock aggregates,

- Need a method that causes little disturbance to estimate RQD,

- Perform periodic surveys and archive data in a easily retrievable manner,

- Should Investigate all variables effecting abrasion resistance not solely abrasion UCS and rock properties,

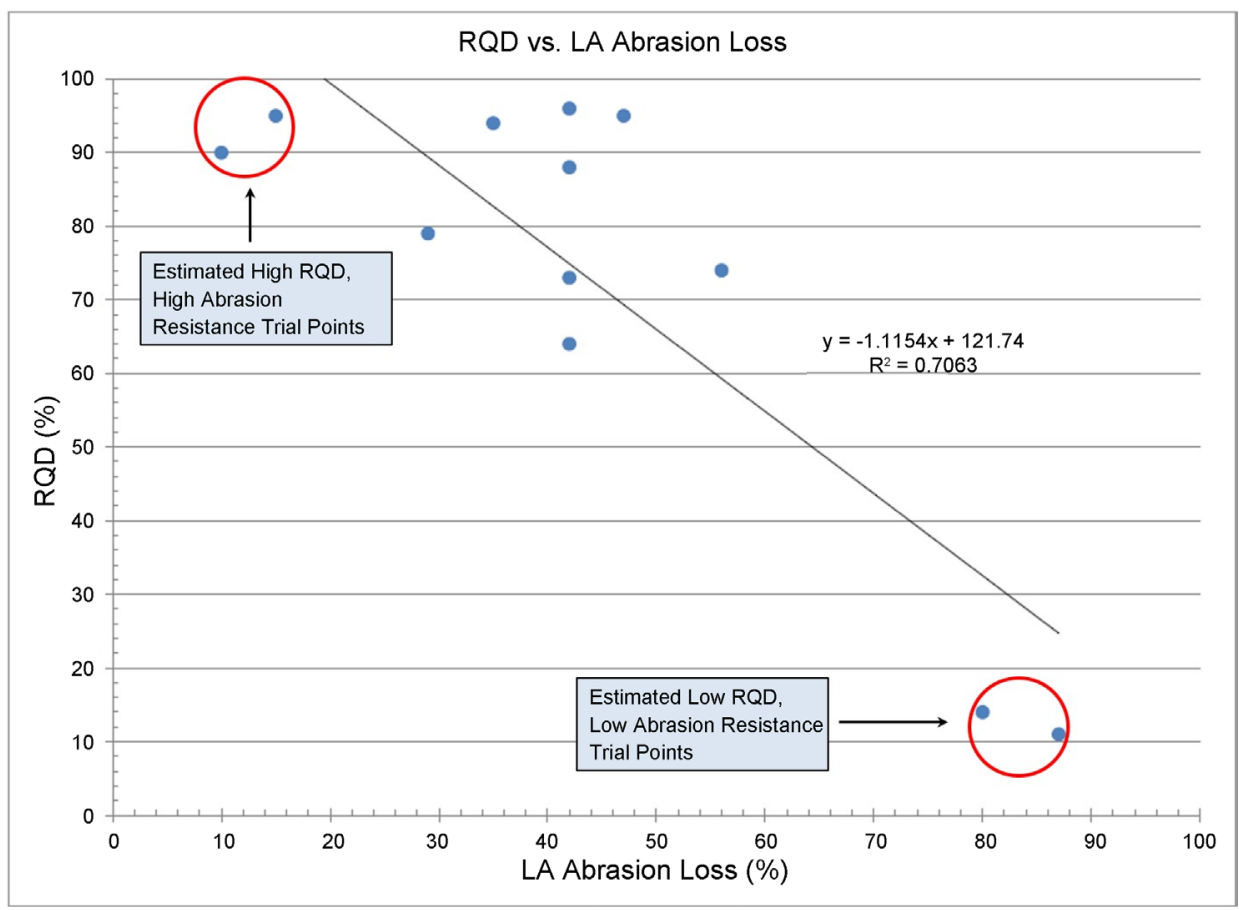

Figure 11. Estimation of RQD vs. LA abrasion loss with four extra data points. 
- Perform other abrasion resistance testing methods,

- Create funding for many rock testing specimens.

Hopefully in the near future, rock abrasion resistance can be shown to provide dependable estimates and correlations to other rock properties.

\section{References}

[1] Okubo, S., Kukui, K. and Nishimatsu, Y. (2011) Estimating Abrasivity of Rock by Laboratory and in Situ Tests. Journal of Rock Mechanics and Rock Engineering, 44, 231-244. https://doi.org/10.1007/s00603-010-0113-6

[2] Yavuz, H., Ugur, I. and Demirdag, S. (2008) Abrasion Resistance of Carbonate Rocks Used in Dimension Stone Industry and Correlations between Abrasion and Rock Properties. International Journal of Rock Mechanics \& Mining Sciences, 45, 260-267.

[3] Cargill, J.S. and Shakoor, A. (1990) Evaluation of Empirical Methods for Measuring Uniaxial Compressive Strength of Rock. International Journal of Rock Mechanics, Mining Science and Geomechanics Abstract, 27, 495-503.

[4] Kılıç, A. and Teymen, A. (2008) Determination of Mechanical Properties of Rocks Using Simple Methods. Bulletin of Engineering Geology and the Environment, 67, 237-244.

[5] Petrica, M., Badisch, E. and Peinsitt, T. (2013) Abrasive Wear Mechanisms and Their Relation to Rock Properties. Wear, 308, 86-94.

[6] Kahraman, S. and Gunaydin, O. (2007) Predicting the Los Angeles Abrasion Loss of Rock Aggregates from the Uniaxial Compressive Strength. Materials Letters, 61, 4861-4865.

[7] Call \& Nicholas, Inc. (2006) Relationship between Hardness, Consistency and Uniaxial Compressive Strength Table. Tucson.

[8] Deere, D.U., Hendron, A.J., Patton, F.D. and Cording, E.J. (1967) Design of Surface and Near Surface Construction in Rock. Failure and Breakage of Rock, Proceedings of 8 th US Symposium of Rock Mechanics, New York, 237-302.

[9] Marinos, P. and Hoek, E. (2000) GSI-A Geologically Friendly Tool for Rock Mass Strength Estimation. Proceedings of GeoEng 2000 Conforence, Melbourne.

[10] Bieniawski, Z.T. (1989) Engineering Rock Mass Classifications. Wiley, New York.

[11] Kahraman, S. and Fener, M. (2007) Empirical Methods to Predict the Abrasion Resistance of Rock Aggregates. Bulletin of Engineering Geology Environmental, 66, 449-455. https://doi.org/10.1007/s10064-007-0093-2 
Submit or recommend next manuscript to SCIRP and we will provide best service for you:

Accepting pre-submission inquiries through Email, Facebook, LinkedIn, Twitter, etc. A wide selection of journals (inclusive of 9 subjects, more than 200 journals)

Providing 24-hour high-quality service

User-friendly online submission system

Fair and swift peer-review system

Efficient typesetting and proofreading procedure

Display of the result of downloads and visits, as well as the number of cited articles Maximum dissemination of your research work

Submit your manuscript at: http://papersubmission.scirp.org/

Or contact ojce@scirp.org 